Case

Report

\title{
Profuse Mediastinal Hemorrhage due to Mediastinitis after a Sternal Infection
}

\author{
Mitsuhiro Kamiyoshihara, MD, PhD, ${ }^{1}$ Takashi Ibe, MD, PhD,${ }^{1}$ Hitoshi Igai, MD, PhD, ${ }^{1}$ \\ Natsuko Kawatani, MD, ${ }^{1}$ Hiroki Hayashi, MD ${ }^{2}$ Kimihiro Shimizu, MD, PhD, ${ }^{3}$ \\ and Izumi Takeyoshi, $\mathrm{MD}, \mathrm{PhD}^{3}$
}

\begin{abstract}
A 79-year-old female patient was admitted because of profuse bleeding from a skin defect in the anterior chest due to a deep sternal wound infection. Eighteen years earlier, she had undergone irradiation to treat a sternal metastasis from breast cancer. Computed tomography $(\mathrm{CT})$ showed the extravasation of iodinated contrast material from the ascending aorta. The patient underwent an immediate thoracotomy and recovered. This report presents a very rare case of massive bleeding from the thoracic aorta due to a mediastinal infection after irradiation for sternal metastasis from breast cancer.
\end{abstract}

Keywords: ascending aorta, bleeding, mediastinal infection, sternal wound infection

\section{Introduction}

Aortic hemorrhage is relatively less common in cases of sternal infection. In addition, mediastinitis is a serious complication after median sternotomy, ${ }^{1)}$ but has rarely been described to induce a fatal spontaneous hemorrhage. We describe a very rare case of aortic hemorrhage due to mediastinal infection after irradiation for sternal bone metastasis.

\section{Case Report}

A 79-year-old female patient was admitted because of

${ }^{1}$ Department of General Thoracic Surgery, Maebashi Red Cross Hospital, Maebashi, Gunma, Japan

${ }^{2}$ Department of Cardiovascular Surgery, Maebashi Red Cross Hospital, Maebashi, Gunma, Japan

${ }^{3}$ Department of Thoracic and Visceral Organ Surgery, Gunma University Graduate School of Medicine, Maebashi, Gunma, Japan

Received: February 24, 2013; Accepted: May 27, 2013

Corresponding author: Mitsuhiro Kamiyoshihara, MD, $\mathrm{PhD}$. Department of General Thoracic Surgery, Maebashi Red Cross Hospital, 3-21-36 Asahi-Cho, Maebashi, Gunma 371-0014, Japan Email: micha2005jp@yahoo.co.jp

(C)2014 The Editorial Committee of Annals of Thoracic and Cardiovascular Surgery. All rights reserved. profuse bleeding from a deep sternal wound infection. The patient had undergone a radical mastectomy for right-sided breast cancer 34 years earlier. Eighteen years earlier, a solitary bone metastasis had been detected in the sternum, and radiation therapy was performed. Nine months earlier, the skin of the anterior chest underwent necrotic changes. A physician diagnosed sternal osteomyelitis with methicillin-resistant Staphylococcus aureus infection based on bacterial cultures. Despite intravenous bacteriostatic agents, including vancomycin, the signs of infection continued, and the condition of the anterior chest skin deteriorated. A physician irrigated the sternum and anterior mediastinum through the skin defect with normal saline. Eight months after the signs of infection were first seen, hemorrhage occurred from the skin defect in the anterior chest through the mediastinum. Consequently, the patient was transferred to our hospital emergency room.

Computed tomography (CT) showed the extravasation of iodinated contrast material between the infected sternum and ascending aorta. Three-dimensional CT (using a 64-row multislice Aquilion ${ }^{\mathrm{TM}}$ 64, Toshiba Medical Systems, Tokyo, Japan) showed an irregular shape in the arterial wall (Fig. 1). We suspected bleeding from the internal mammary artery and performed emergency surgery to remove the necrotic skin, infectious/fragile 

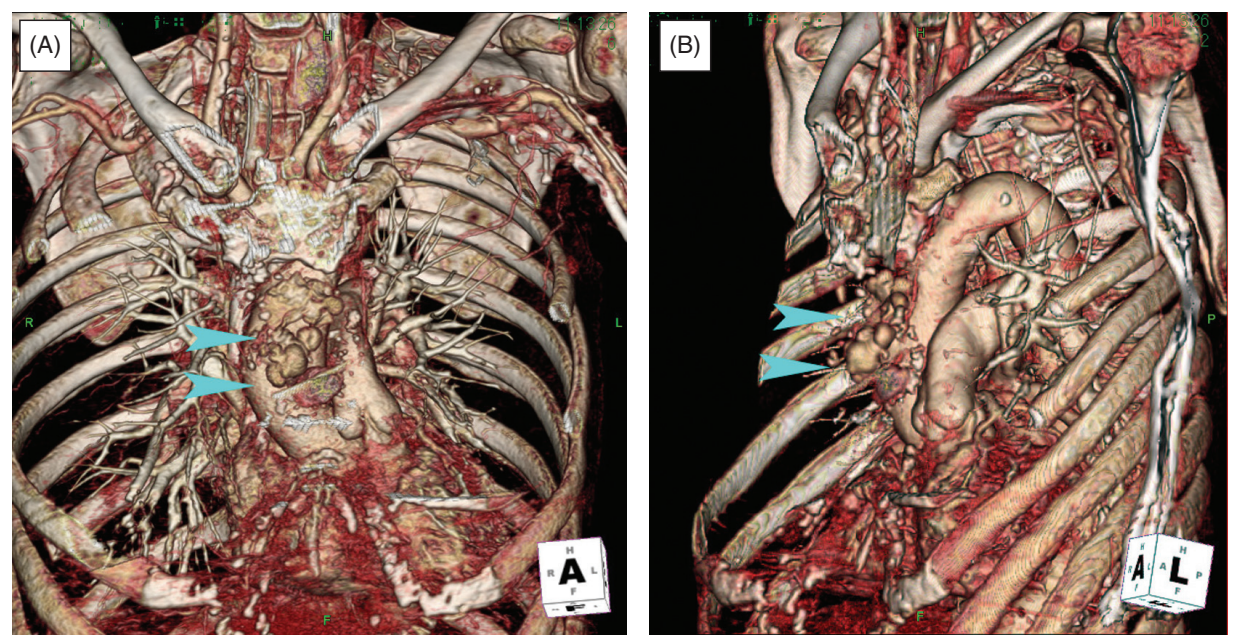

Fig. 1 Three-dimensional computed tomography (3D-CT) images. (A) Anterior and (B) left anterolateral views. Arrowheads show the extravasation of iodinated contrast material from the ascending aorta.

sternum, and clotted blood. Then, there was a sudden eruption of the blood from the anterior aspect of the ascending aorta, which proved to be due to a perforation a few millimeters in diameter. We put a purse-string suture around the perforation and were able to control the bleeding. The defect in the sternum remained and the anterior mediastinum was left open. Subsequently, open mediastinal irrigation was performed.

On hospital-day 8, the patient was weaned from ventilator support. On day 9, she was transferred from the intensive care unit to a general ward. On day 30, she collapsed and hemorrhaged from the mediastinum. Emergency surgery revealed a rupture of the aortic wall at a different site from the initial hemorrhage. We inserted a purse-string suture at the perforated site using a patch; resuscitation was successful. The mediastinal irrigation was restarted and continued.

On day 42, we performed mediastinal debridement and reconstructed the anterior chest wall with a pedicled major pectoral muscle flap with a skin pedicle. The debrided mediastinal structures were covered with the muscle graft. On day 44, she was transferred from the intensive care unit to a general ward. The subsequent postoperative course was uneventful, and the patient was transferred to her previous hospital on day 53.

\section{Discussion and Conclusion}

The English literature includes a report of a deep sternal wound infection that caused right ventricle rupture, which is a potentially fatal complication that occurs in $5 \%-21 \%$ of conventionally treated deep sternal wound infections. ${ }^{2-5)}$ However, no case similar to ours was found in the English literature in a PubMed search (available at http://www.ncbi.nlm.nih.gov/pubmed/), using "rupture" and "hemorrhage" connected with "mediastinitis" as index words. This is the first report of an ascending aorta hemorrhage due to recurrent mediastinal infection after irradiation for sternal bone metastasis from breast cancer.

El Oakley, et al. ${ }^{1)}$ proposed the following classification of mediastinitis after a median sternotomy. Type I mediastinitis presents within 2 weeks postoperatively, while type II presents in 2-6 weeks. When types I and II have one or more associated risk factors, they are upgraded to types IIIA and IIIB, respectively. If one therapeutic trial fails, then failed types I-III become type IVA. If more than one therapy fails, the mediastinitis is classified as type IVB. Mediastinitis occurring more than 6 weeks postoperatively is type V. Our patient did not undergo a median sternotomy, but we feel that our case could be categorized as type V.

There is a possibility that the radiation caused not only the skin necrosis and infection that extended to the mediastinum but also the aortic rupture. Poon, et al. ${ }^{6}$ postulated that infection combined with radiation damage may trigger the breakdown of tissues. They presented both microscopic and ultrastructural changes in a human aorta that ruptured 5 months after radiation therapy for esophageal cancer. Their autopsy findings showed that the ruptured portion of the aorta revealed sharply demarcated necrosis of the entire wall. The elastic fibers in this region showed complete breakdown 
without any cellular reaction. Electron microscopy showed that the radiated aorta exhibited preservation of collagen fibers and smooth muscle, but slit-like spaces in individual elastic laminae were noted. There was irregular fragmentation of the elastic fibers with nonreactive radiation necrosis at the site of rupture. Himmel, et al. ${ }^{7)}$ reviewed radiation-induced chronic arterial injury. They noted patterns of injury to human vessels exposed to therapeutic doses of radiation, $\left.{ }^{8}\right)$ such as subendothelial connective tissue proliferation, disruption of the elastic lamina, accumulation of intimal and subintimal fibrinoid substances, degeneration of smooth muscle, dense fibrosis of the adventitia, aggregates of foamy histiocytes in the damaged wall, and eventual obliteration of the vasa vasorum..$^{7,9)}$

Gram-positive bacteria are the organisms isolated most commonly in mediastinitis; S. aureus or S. epidermidis is identified in $70 \%-80 \%$ of cases. ${ }^{10,11)}$ Mixed infections can account for up to $40 \%$ of cases. ${ }^{12)}$ Gram-negative organisms and fungal infections are infrequently incriminated as the main cause of mediastinitis. ${ }^{13)}$

The treatment of mediastinitis varies from simple prolonged antibiotic therapy ${ }^{14)}$ to a complete sternectomy combined with a major plastic procedure. ${ }^{15-17)}$ Similarly, wound incision and drainage alone carries a mortality rate of $23 \%$ and a failure rate of $39 \% .{ }^{14)}$ Therefore, prolonged antibiotic therapy alone for mediastinitis is not acceptable. If antibiotic therapy, drainage, or irrigation is abandoned, we must decide the surgical treatment as a matter of course.

The Lund University Hospital mediastinitis algorithm is a systematic approach for treatment decisions to handle postoperative mediastinitis. Secondary wound closure is recommended after systemic antibiotic treatment for 4-6 weeks, if the C-reactive protein levels are below $7 \mathrm{mg} / \mathrm{dl} .{ }^{18)}$ Ultimately, we believe that the timing of chest closure depends on the surgeon's experience and evaluation of the local status.

\section{Disclosure Statement}

The authors declare that they have received no financial support and have no relationships that may pose a conflict of interest.

\section{References}

1) El Oakley RM, Wright JE. Postoperative mediastinitis: classification and management. Ann Thorac
Surg 1996; 61: 1030-6.

2) Yellin A, Refaely Y, Paley M, et al. Major bleeding complicating deep sternal infection after cardiac surgery. J Thorac Cardiovasc Surg 2003; 125: 554-8.

3) Arbulu A, Gursel E, Camero LG, et al. Spontaneous right ventricular rupture after sternal dehiscence: a preventable complication? Eur J Cardiothorac Surg 1996; 10: 110-5.

4) Cartier R, Diaz OS, Carrier M, et al. Right ventricular rupture. A complication of postoperative mediastinitis. J Thorac Cardiovasc Surg 1993; 106: 1036-9.

5) Khoynezhad A, Abbas G, Palazzo RS, et al. Spontaneous right ventricular disruption following treatment of sternal infection. J Card Surg 2004; 19: 74-8.

6) Poon TP, Kanshepolsky J, Tchertkoff V. Rupture of the aorta due to radiation injury. Report of a case and electron microscopic study. JAMA 1968; 205: 875-8.

7) Himmel PD, Hassett JM. Radiation-induced chronic arterial injury. Semin Surg Oncol 1986; 2: 225-47.

8) Thomas E, Forbus WD. Irradiation injury to the aorta and to the lung. Arch Pathol 1958; 67: 256-63.

9) White DC. The histopathologic basis for functional decrements in late radiation injury in diverse organs. Cancer 1976; 37: 1126-43.

10) Grossi EA, Culliford AT, Krieger KH, et al. A survey of 77 major infectious complications of median sternotomy: a review of 7,949 consecutive operative procedures. Ann Thorac Surg 1985; 40: 214-23.

11) Demmy TL, Park SB, Liebler GA, et al. Recent experience with major sternal wound complications. Ann Thorac Surg 1990; 49: 458-62.

12) Sarr MG, Gott VL, Townsend TR. Mediastinal infection after cardiac surgery. Ann Thorac Surg 1984; 38: 415-23.

13) Kohman LJ, Coleman MJ, Parker FB. Bacteremia and sternal infection after coronary artery bypass grafting. Ann Thorac Surg 1990; 49: 454-7.

14) Serry C, Bleck PC, Javid H, et al. Sternal wound complications. Management and results. J Thorac Cardiovasc Surg 1980; 80: 861-7.

15) Lee AB, Schimert G, Shaktin $S$, et al. Total excision of the sternum and thoracic pedicle transposition of the greater omentum; useful strategems in managing severe mediastinal infection following open heart surgery. Surgery 1976; 80: 433-6.

16) Pairolero PC, Arnold PG. Management of recalcitrant median sternotomy wounds. J Thorac Cardiovasc Surg 1984; 88: 357-64.

17) Jurkiewicz MJ, Bostwick J, Hester TR, et al. Infected median sternotomy wound. Successful treatment by muscle flaps. Ann Surg 1980; 191: 738-44.

18) Sjögren J, Malmsjö M, Gustafsson R, et al. Poststernotomy mediastinitis: a review of conventional surgical treatments, vacuum-assisted closure therapy and presentation of the Lund University Hospital mediastinitis algorithm. Eur J Cardiothorac Surg 2006; 30: 898-905. 